CLINICAL STUDY

\title{
Genotypes associated with lipid metabolism contribute to differences in serum lipid profile of GH-deficient adults before and after GH replacement therapy
}

\author{
Edna J L Barbosa ${ }^{1,2, *}$, Camilla A M Glad ${ }^{1,3, *}$, Anna G Nilsson ${ }^{1}$, Helena Filipsson Nyström ${ }^{1}$, Galina Götherström ${ }^{1}$, \\ Per-Arne Svensson $^{3}$, Isabela Vinotti ${ }^{2}$, Bengt-Åke Bengtsson ${ }^{1}$, Staffan Nilsson ${ }^{4}$, Cesar Luiz Boguszewski ${ }^{2}$ \\ and Gudmundur Johannsson ${ }^{1}$ \\ ${ }^{1}$ Department of Endocrinology, Institute of Medicine, Sahlgrenska Academy, Sahlgrenska University Hospital, University of Gothenburg, Gröna Straket 8 , \\ SE-413 45 Gothenburg, Sweden, ${ }^{2}$ SEMPR, Servico de Endocrinologia e Metabologia do Hospital de Clínicas da Universidade Federal do Paraná, 80030- \\ 110 Curitiba, Brazil, ${ }^{3}$ Department of Molecular and Clinical Medicine, Institute of Medicine, Sahlgrenska Academy, Sahlgrenska Center for Cardiovascular \\ and Metabolic Research, University of Gothenburg, SE-413 45 Gothenburg, Sweden and ${ }^{4}$ Department of Mathematical Statistics, Institute of \\ Mathematical Sciences, Chalmers University of Technology, Chalmers, SE-41296 Gothenburg, Sweden
}

(Correspondence should be addressed to E J L Barbosa at Department of Endocrinology, Institute of Medicine, Sahlgrenska Academy, Sahlgrenska University Hospital, University of Gothenburg; Email: edna.barbosa@medic.gu.se)

*(E J L Barbosa and C A M Glad contributed equally to this work)

\begin{abstract}
Objective: GH deficiency (GHD) in adults is associated with an altered serum lipid profile that responds to GH replacement therapy (GHRT). This study evaluated the influence of polymorphisms in genes related to lipid metabolism on serum lipid profile before and after 1 year of GHRT in adults.

Design and methods: In 318 GHD patients, total cholesterol (TC) serum concentrations, LDL-C, HDL-C, and triglycerides (TG) were assessed. Using a candidate gene approach, 20 single nucleotide polymorphisms (SNPs) were genotyped. GH dose was individually titrated to obtain normal serum IGF1 concentrations.

Results: At baseline, the minor alleles of cholesteryl ester transfer protein (CETP) gene SNPs rs708272 and rs1800775 were associated with higher serum TC and apolipoprotein E (APOE) gene SNP rs7412 with lower TC concentrations; CETP SNPs rs708272, rs1800775, and rs3764261 and apolipoprotein B (APOB) gene SNP rs693 with higher serum HDL-C; APOE SNP rs7412, peroxisome proliferatoractivated receptor gamma (PPARG) gene SNP rs10865710 with lower LDL-C, and CETP SNP rs1800775 with higher LDL-C; and APOE/C1/C4/C2 cluster SNP rs35136575 with lower serum TG. After treatment, $A P O B$ SNP rs676210 GG genotype was associated with larger reductions in TC and LDL-C and PPARG SNP rs10865710 CC genotype with greater TC reduction. All associations remained significant when adjusted for age, sex, and BMI.

Conclusions: In GHD adults, multiple SNPs in genes related to lipid metabolism contributed to individual differences in baseline serum lipid profile. The GH treatment response in TC and LDL-C was influenced by polymorphisms in the $A P O B$ and PPARG genes.
\end{abstract}

European Journal of Endocrinology 167 353-362

\section{Introduction}

GH has several important effects on lipid metabolism. GH increases the number and activity of hepatic lowdensity lipoprotein (LDL) receptors, which enables LDL catabolism and enhances the activity of cholesterol $7 \alpha$-hydroxylase, the rate-limiting enzyme in bile acid synthesis (1). Moreover, GH enhances lipoprotein turnover by inducing lipolysis and plasma-free fatty acid availability and increasing very low-density lipoprotein (VLDL) output from the liver (2).

GH deficiency (GHD) in adults is characterized by an atherogenic lipid profile with increased total cholesterol (TC) and LDL-C, increased apolipoprotein B $(\mathrm{APOB})$ and, in some reports, increased triglycerides (TG), and reduced HDL-C concentrations (2). GH replacement therapy (GHRT) in GHD adults has been associated with reduced TC and LDL-C. However, as observed with other end points of GHRT, there is considerable individual variability in the treatment response (3). A meta-analysis of placebo-controlled studies showed that GHRT was associated with a mean reduction of $-0.3 \pm 0.3 \mathrm{mmol} / \mathrm{l}$ in $\mathrm{TC}$ and $-0.5 \pm 0.3 \mathrm{mmol} / \mathrm{l}$ in LDL-C (4). Conversely, HDL-C concentrations have been reported to have increased (4), remain unchanged (5), or to decrease (6) after GHRT. 
Gender, age, BMI, GH dose, and the estrogen replacement route in women have been linked with the response to $\operatorname{GHRT}(7,8,9)$, but these clinical factors have limited power for predicting the variability in GH-mediated effects (3). More recently, the impact of the $\mathrm{GH}$ receptor (GHR) gene polymorphism on $\mathrm{GH}$ response was evaluated, with data for both children and adults showing either little $(10,11,12)$ or no influence $(13$, 14) on the GHR genotype. Dullaart et al. (15) have reported on an association of the HDL-C response to GHRT with single nucleotide polymorphism (SNP) rs1800775 in the cholesteryl ester transfer protein (CETP) gene, which was modified by concomitant glucocorticoid administration. However, it remains unknown whether additional SNPs in genes related to lipid metabolism contribute to variations in the lipid profile of GHD adults as well as to their changes after GHRT. Therefore, our aim was to evaluate whether gene polymorphisms previously shown to influence serum lipid concentrations in other populations $(16,17,18$, $19,20,21,22,23)$ could have an impact on the lipid profile of GHD adults and influence changes in serum lipid concentrations in response to GHRT.

\section{Materials and methods}

\section{Patients}

The patients enrolled in this study are part of a larger longitudinal cohort of adults with hypopituitarism and GHD $(n=457)$ treated at the Sahlgrenska University Hospital, Gothenburg, Sweden. From this cohort, we excluded patients who refused genetic testing $(n=51)$, with missing data during their 12 months of GHRT $(n=50)$, enrolled in another study $(n=25)$ and with compliance problems $(n=13)$. Therefore, a total of 318 GHD adults (184 men) with a mean age of 49.7 (range 17-77) year, who were eligible for GHRT, were selected for our protocol. The clinical characteristics of the patients are shown in Table 1. The diagnosis of GHD was confirmed by a GH stimulation test $(77.7 \%$ insulin tolerance test, $6.6 \%$ GHRH-arginine, 2.5\% GHRHpyridostigmine, and $0.6 \%$ glucagon) or a low serum IGF1 concentration together with three or more pituitary hormone deficiencies (12.6\%) (24). Two hundred and eighty-seven patients had adult-onset GHD (AO-GHD) and 31 cases were childhood-onset GHD (CO-GHD). None of the AO-GHD patients had previously received GH treatment. CO-GHD had previously received GH therapy but it had been terminated at least 4 years before they were retested before GHRT in adulthood. Patients with previous treatment for Cushing's disease (20) and acromegaly (12) were in remission before entering the study and fulfilled international diagnostic criteria for GHD (24). Overall, nonfunctioning pituitary adenoma was the most frequent etiology of GHD (40.6\%). When required, patients received adequate and stable replacement therapy with glucocorticoids, thyroid hormone, sex steroids, and desmopressin for at least 6 months before starting GHRT. Fifty percent required a mean hydrocortisone dose of $19.9 \pm 7.2 \mathrm{mg} /$ day and $74 \%$ required a mean levothyroxine dose of $108 \pm 40 \mu \mathrm{g} /$ day. Of 134 women, 60 received oral $(n=45)$ or transdermal $(n=15)$ estrogen therapy, while all hypogonadal (138 out of 184) men received testosterone by an i.m. $(n=114)$ or transdermal $(n=24)$ route. Twenty-eight

Table 1 Baseline clinical characteristics of the 318 adults with GHD. Results are shown as median (percentiles 25, 75) or percentage.

\begin{tabular}{lclc}
\hline Etiology & $\boldsymbol{n}(\%)$ & Clinical parameters & Value $(n(\%))$ \\
\hline Nonfunctioning adenoma & $129(40.6)$ & Male & $184(57.9)$ \\
Idiopathic & $28(8.8)$ & Female & $134(42.1)$ \\
Prolactinoma & $24(7.5)$ & Age (year) & $51(41.2,60.5)$ \\
Craniopharyngioma & $24(7.5)$ & Current smoker & $81(25.5)$ \\
Hypophysitis & $22(6.9)$ & GH peak $(\mu \mathrm{g} /)^{\mathrm{a}}$ & $0.41(0.1,1.2)$ \\
Previous Cushing's disease & $20(6.3)$ & AO-GHD & $287(90.3)$ \\
& $12(3.8)$ & CO-GHD & $31(9.7)$ \\
Previous acromegaly & & MPHD & $281(88.4)$ \\
& $59(18.6)$ & Duration hypopituitarism (year) & $37(11.6)$ \\
Other etiologies & & Duration GHD (year) & $2.0(1.0,10.0)$ \\
Prestudy treatment & $166(52.2)$ & ACTH deficiency & $1.0(1.0,4.0)$ \\
Surgery & $23(7.2)$ & TSH deficiency & $160(50)$ \\
Radiotherapy & $51(16)$ & LH/FSH substitution therapy & $235(74)$ \\
Surgery +radiotherapy & & Men & $138 / 184(75)$ \\
& & Women & $60 / 134(44.8)$ \\
& & ADH deficiency & $51(16)$ \\
\hline
\end{tabular}

MPHD, multiple pituitary hormone deficiency; IGHD, isolated GHD.

${ }^{\mathrm{a}} \mathrm{GH}$ peak, GH response to provocative tests in order to diagnose GHD.

${ }^{b}$ Empty sella, meningioma, apoplexy, Sheehan, trauma, sarcoidosis, cystic lesion, histiocytosis, congenital hypopituitarism, dysgerminoma, granular cells tumor, hamartoma, medulloblastoma, rhabdomyosarcoma, septo-optic dysplasia, TSH adenoma, and Wegener granulomatosis. 
(8.8\%) patients were on lipid-lowering drugs during the study period. The dose and type of lipid-lowering drugs were adjusted when required.

\section{Study design}

Patients were prospectively enrolled in an open-label treatment protocol. After initial measurements were obtained, all patients received recombinant human $\mathrm{GH}$, administered s.c. every evening, with an initial mean \pm s.D. dose of $0.23 \pm 0.23 \mathrm{mg} /$ day, which was titrated after 1 and 4 weeks of GHRT and every 3 months subsequently to maintain age- and sex-adjusted serum IGF1 levels between the mean and the upper limit of the normal reference range.

Written informed consent was obtained from all patients. The study was approved by the ethics committee at the University of Gothenburg, Sweden, and performed in accordance with the Declaration of Helsinki.

\section{Biochemical assays}

Serum IGF1 levels were determined in serum samples collected after an overnight fast, using a hydrochloric acid-ethanol extraction RIA with authentic serum IGF1 for labeling (Nichols Institute Diagnostics, San Juan Capistrano, CA, USA). After June 2004, the levels were determined using an automated chemiluminescent immunoassay (Advantage) from Nichols. From September 2006, serum IGF1 was determined using an automated chemiluminescent assay system (IMMULITE 2500, Diagnostic Products Corp., Los Angeles, CA, USA). All assays had a detection limit $\leq 20 \mu \mathrm{g} / \mathrm{l}$ and an interassay $\mathrm{CV} \leq 8.6 \%$. The individual serum IGF1 levels were transformed into SDS according to age- and sexadjusted reference values $(25,26)$.

TC and TG concentrations were determined using enzymatic methods (Roche Molecular Biochemicals) and expressed as mmol/l. The interassay $\mathrm{CV}$ for TC and TG determinations were 2.9 and $3.8 \%$ respectively, and intra-assay $\mathrm{CV}$ were 0.9 and $1.1 \%$ respectively. HDL-C levels were determined after the precipitation of APOBcontaining lipoproteins with $\mathrm{MgCl}_{2}$ and heparin (27). LDL-C was calculated using Friedewald's formula adjusted to SI units (28).

\section{Anthropometric parameters}

Body weight, body height (BH), and BMI were determined as previously reported (3). Waist circumference was measured in the standing position with a flexible plastic tape placed midway between the lower rib margin and the iliac crest; hip girth was measured at the widest part of the hip. Systolic and diastolic blood pressures were measured after at least $5 \mathrm{~min}$ of supine rest using the sphygmomanometric cuff method.

\section{Selection of candidate genes and SNPs}

The selection of candidate genes was based on their physiological function in lipid metabolism and cardiovascular health according to previous publications. Further selection of candidate SNPs in the genes was also based on earlier reports on functionality and/or associations with clinical end points. Due to the limited size of our cohort, SNPs with an allele frequency below $10 \%$ in the HapMap-CEU Panel (when data were available in the Entrez SNP database) were not included.

The following genes and SNPs were included: $A P O B$ gene (APOB: SNPs rs676210, rs1042031, rs679899, rs562338, and rs693) (16); LDL receptor (LDLR: rs1433099 and rs2738466) (17); lipoprotein lipase (LPL: rs1801177, rs12678919, and rs6993414) (17, 18); CETP gene (CETP: $-629 \mathrm{C}>\mathrm{A}$ (rs1800775), TaqIB polymorphism (rs708272), and rs3764261) (15, 17, 19); apolipoprotein E (APOE gene: SNPS rs429358 and rs7412, which together define the APOE $\varepsilon 2$, APOE \&3, and $A P O E$ \&4) (20); $\mathrm{APOE} / \mathrm{C} 1 / \mathrm{C} 4 / \mathrm{C} 2$ gene cluster (APOE/C1/C4/C2: rs35136575 and rs4420638) (21); peroxisome proliferator-activated receptor gamma (PPARG: rs10865710) (22); proprotein convertase subtilisin kexin type 9 (PCSK9: rs11206510) (17); and nuclear receptor subfamily 3 , group $C$, member 2 (NR3C2: rs5522) (23).

\section{Genetic analyses}

Genomic DNA was isolated from whole blood using the Flexigene DNA kit (Qiagen). SNP rs429358 in the APOE gene was genotyped using TaqMan SNP genotyping and the remaining SNPs with the Sequenom platform.

In the TaqMan SNP genotyping, 10 ng genomic DNA was added to a reaction mix containing $1 \times$ TaqMan Genotyping PCR Master Mix (Applied Biosystems, Foster City, CA, USA) and rs429358-specific genotyping assay purchased from Applied Biosystems (C_3084793_20). All reactions were carried out in $5 \mu \mathrm{l}$ reactions on 384well plates (Applied Biosystems). PCR amplification was performed using a 384 dual GeneAMP PCR system 9700 instrument (Applied Biosystems), and allele detection was carried out in an ABI Prism 7900HT Sequence Detection System instrument (Applied Biosystems).

The Sequenom genotyping was performed at the Mutation Analysis facility at Karolinska University Hospital using matrix-assisted laser desorption/ionization time-of-flight (MALDI-TOF) mass spectrometry (Sequenom, Inc., San Diego, CA, USA). iPLEX assays were designed using SpectroDESIGNER software (Sequenom, Inc.). Amplification was performed in a total volume of $5 \mu \mathrm{l}$ containing $10 \mathrm{ng}$ genomic DNA, $100 \mathrm{nM}$ of each amplification primer, $500 \mathrm{mM} \mathrm{dNTP} \mathrm{mix,}$ $1.625 \mathrm{mM} \mathrm{MgCl}_{2}$, and 0.5 units of HotStarTaq DNA Polymerase (Qiagen, Inc.). The reaction was subjected to the following PCR conditions: a single cycle of denaturation at $95^{\circ} \mathrm{C}$ for $15 \mathrm{~min}$, followed by 45 cycles 
at $94{ }^{\circ} \mathrm{C}$ for $20 \mathrm{~s}, 56^{\circ} \mathrm{C}$ for $30 \mathrm{~s}, 72{ }^{\circ} \mathrm{C}$ for $60 \mathrm{~s}$, and a final extension at $72^{\circ} \mathrm{C}$ for $3 \mathrm{~min}$. The allele-specific extension was performed in a total volume of $9 \mu \mathrm{l}$ using $5 \mathrm{pmol}$ of extension primer and the Mass EXTEND Reagent Kit and cleaned using SpectroCleaner (Sequenom, Inc.). Primer sequences are given in Supplementary Table 1, see section on supplementary data given at the end of this article. Products from primer extension reactions were loaded on a 384-element chip nanoliter pipetting system (Sequenom, Inc.) and analyzed on a MassARRAY Compact mass spectrometer (Sequenom, Inc.). The genotype calls were manually checked by two individuals separately using the SpectroTYPER RT 4.0.5 software (Sequenom, Inc.). The genotyping was validated using a set of 14 trio families, totaling 42 individuals, with genotype data available through the HapMap consortium (HapMap data release 24/phase II).

\section{Statistical analysis}

Statistical analysis was performed using SPSS for Windows, version 17.0 (SPSS, Inc., Chicago, IL, USA). Paired-samples Student's $t$-tests were used to compare values at baseline and after 1 year of GHRT. Based on genotype, patients were divided into two groups: i) patients with two major alleles; and ii) patients carrying at least one minor allele. Genetic association of individual SNPs to the lipid concentrations as well as to their 1-year changes was analyzed with a two-sample $t$-test and ANCOVA, adjusting for significant covariates among sex, age, and baseline BMI. While the lipids are slightly right skewed and therefore usually log transformed, this transformation was not done as the ANCOVA had a better fit with untransformed data, and the interpretation is more straightforward. For $A P O E$ gene, we also inferred the haplotypes $\varepsilon 2, \varepsilon 3$, and $\varepsilon 4$ from the haplotypes defined by rs 429358 and rs7412 in that order, where $\varepsilon 2=\mathrm{T}-\mathrm{T}$, $\varepsilon 3=\mathrm{C}-\mathrm{T}$, and $\varepsilon 4=\mathrm{C}-\mathrm{C}$, followed by haplotype regression, adjusting for covariates. $P<0.05$ was assumed to represent a significant difference. Correction for multiple testing was done by permutation for the 88 tests related to changes in lipid concentrations.

\section{Results}

\section{Genotyping}

All genotyping assays had a success rate $>94.9 \%$. Additionally, after the Sequenom run, regenotyping of $27 \%$ of the study samples resulted in $99.9 \%$ concordance. No Mendelian errors were found in the 14 HapMap families and concordance analyses with the HapMap data showed concordance rates of $100 \%$ for all analyzed SNPs available in HapMap, except for SNPs rs1800775 in the CETP gene ( $90 \%$ concordance) and rs12678919 in the LPL gene (95\% concordance); the HapMap data from these two SNPs gave rise to
Mendelian errors. No genotype data were available for the following SNPs: CETP SNP rs708272, LPL SNP rs1801177, APOE SNP rs7412, and APOE/C1/C4/C2 SNP rs35136575 from the HapMap consortium. Minor allele frequencies (MAF), genotype distributions, and concordance with Hardy-Weinberg equilibrium (HWE) of the 20 SNPs are shown in Table 2. All SNPs conformed to HWE $(P>0.05)$, except for $A P O B$ SNP rs562338. As this deviation was mild $(P=0.01)$ and the observed MAF (0.147) was similar to that reported in the Entrez SNP database (0.221) from the HapMapCEU panel, this SNP was maintained in the analysis.

\section{Effects of GH replacement on lipid profile}

The median daily GH dose after 1 year of therapy was 0.40 (range 0.1-1.5) mg. Serum concentrations of IGF1, HDL-C, and glucose increased; TC and LDL-C concentrations decreased; and TG did not change with GHRT (Table 3). There was a reduction in waist circumference and waist/hip ratio, but no changes in blood pressure, weight, and BMI.

\section{Genotype and baseline lipid profile}

Table 4 summarizes the SNPs significantly associated with serum lipid concentrations at baseline. All associations between SNPs and baseline lipid concentrations remained significant when adjusted for significant covariates and the use of glucocorticoid and levothyroxine replacement. Additional analyses excluding patients with lipid-lowering drugs $(n=28)$ and patients with previous Cushing's disease $(n=20)$ and acromegaly $(n=12)$ did not alter these results.

The A allele of CETP SNP rs708272 was associated with higher serum TC $(P=0.006)$ and HDL-C concentrations $(P=0.005)$; the A allele of CETP SNP rs1800775 with higher serum TC $(P=0.005)$, HDL-C $(P=0.01)$, and LDL-C concentrations $(P=0.03)$; and the T allele of CETP SNP rs3764261 with higher serum HDL-C concentrations $(P=0.0004)$.

There was a significant association between the $\mathrm{T}$ allele of $A P O B$ SNP rs693 and higher serum HDL-C concentrations $(P=0.02)$. However, the $\mathrm{T}$ allele of APOE SNP rs7412 was associated with lower TC $(P=0.0002)$ and LDL-C concentrations $(P=0.0002)$ and the $\mathrm{G}$ allele of $A P O E / C 1 / C 4 / C 2$ SNP rs35136575 was associated with lower TG concentrations $(P=0.007)$. We also found an association between the $G$ allele PPARG SNP rs10865710 and lower LDL-C concentrations $(P=0.02)$.

\section{Genotype and GH-induced changes in serum lipid concentrations}

Table 5 and Figure 1 summarize the data on SNPs with a statistically significant association with changes in 
Table 2 Summary of the allele frequencies, genotype distributions, and Hardy-Weinberg equilibrium (HWE) of SNPs in genes related to lipid metabolism.

\begin{tabular}{|c|c|c|c|c|c|c|c|c|c|c|}
\hline Gene & SNP & Major (M) & Minor $(m)$ & $\operatorname{MAF}(\mathrm{m})$ & MM & $\mathrm{Mm}$ & $\mathrm{mm}$ & Missing & HWEp & $d^{a}$ \\
\hline$A P O B$ & rs693 & C & $\mathrm{T}$ & 0.465 & 92 & 149 & 70 & 7 & 0.808 & 0.35 \\
\hline$A P O B$ & rs562338 & C & T & 0.147 & 219 & 91 & 0 & 8 & 0.010 & 0.35 \\
\hline$A P O B$ & rs676210 & $\mathrm{G}$ & A & 0.214 & 198 & 101 & 17 & 2 & 0.688 & 0.33 \\
\hline$A P O B$ & rs679899 & G & A & 0.477 & 86 & 152 & 72 & 8 & 0.954 & 0.36 \\
\hline$A P O B$ & rs1042031 & G & A & 0.204 & 201 & 95 & 16 & 6 & 0.562 & 0.33 \\
\hline$L D L R$ & rs1433099 & G & A & 0.267 & 174 & 114 & 27 & 3 & 0.415 & 0.32 \\
\hline$L D L R$ & rs2738466 & A & $\mathrm{G}$ & 0.240 & 180 & 114 & 18 & 6 & 1.000 & 0.32 \\
\hline$L P L$ & rs1801177 & G & A & 0.018 & 299 & 11 & 0 & 8 & 0.951 & 0.86 \\
\hline$L P L$ & rs6993414 & A & G & 0.113 & 251 & 62 & 5 & 0 & 0.875 & 0.39 \\
\hline$L P L$ & rs12678919 & A & $\mathrm{G}$ & 0.096 & 255 & 52 & 4 & 7 & 0.772 & 0.41 \\
\hline CETP & rs $708272^{b}$ & G & A & 0.401 & 119 & 142 & 56 & 1 & 0.488 & 0.33 \\
\hline CETP & rs $1800775^{b}$ & $\mathrm{C}$ & A & 0.441 & 105 & 143 & 68 & 2 & 0.342 & 0.34 \\
\hline CETP & rs3764261 & $\mathrm{G}$ & $\mathrm{T}$ & 0.307 & 160 & 121 & 37 & 0 & 0.173 & 0.32 \\
\hline$A P O E$ & rs7412 ${ }^{\mathrm{c}}$ & C & $T$ & 0.068 & 270 & 36 & 3 & 9 & 0.369 & 0.48 \\
\hline$A P O E$ & rs $429358^{c}$ & $\mathrm{~T}$ & C & 0.169 & 213 & 99 & 4 & 2 & 0.129 & 0.34 \\
\hline$A P O E / C^{\mathrm{d}}$ & rs4420638 & A & G & 0.199 & 200 & 106 & 10 & 2 & 0.666 & 0.33 \\
\hline$A P O E / C^{\mathrm{d}}$ & rs 35136575 & C & $\mathrm{G}$ & 0.260 & 175 & 110 & 26 & 7 & 0.353 & 0.32 \\
\hline PPARG & rs10865710 & C & $\mathrm{G}$ & 0.235 & 177 & 122 & 12 & 7 & 0.269 & 0.32 \\
\hline PCSK 9 & rs11206510 & T & C & 0.165 & 219 & 83 & 10 & 6 & 0.827 & 0.35 \\
\hline$N R 3 C 2$ & rs5522 & A & $\mathrm{G}$ & 0.120 & 244 & 70 & 3 & 1 & 0.710 & 0.37 \\
\hline
\end{tabular}

MAF, minor allele frequency; MM, homozygote for the common (major) allele (two major alleles); Mm, heterozygote (one major allele and one minor allele); $\mathrm{mm}$, homozygote for the rare (minor) allele (two minor alleles).

${ }^{a} d$, the standardized difference detectable with $80 \%$ power at the $5 \%$ significance level for each SNP.

b The former abbreviations for CETP SNP rs708272 is TaqlB polymorphism and for CETP SNP rs 1800775 is -629A/C

${ }^{\mathrm{c}}$ The polymorphisms, rs429358 and rs7412, in the APOE gene together define the APOE $\varepsilon 2, \varepsilon 3$ and $\varepsilon 4$ alleles.

${ }^{\mathrm{d}} A P O E / C$ is an abbreviation for $A P O E / C 1 / C 4 / C 2$ gene cluster.

plasma lipid concentrations in response to GHRT. All associations remained significant when adjusted for age, sex, and BMI and the use of glucocorticoid and levothyroxine replacement. Additional analyses excluding patients with lipid-lowering drugs $(n=28)$ and patients with previous Cushing's disease $(n=20)$ and acromegaly $(n=12)$ did not alter these results.

After GHRT, APOB SNP rs676210 was associated with larger reductions in TC $(P=0.004)$ and LDL-C concentrations $(P=0.024)$ in homozygous $G$ allele carriers. Furthermore, PPARG SNP rs10865710 was associated with greater reduction in TC concentration
$(P=0.01)$ in homozygous $C$ allele carriers. However, these associations were not significant when corrected for multiple testing.

Together, SNPs rs676210 in the $A P O B$ gene and rs108657710 in the PPARG gene explained 5\% of the variance in the TC concentrations after 1 year of GHRT.

\section{Discussion}

In this study, we found that polymorphisms in genes regulating lipid metabolism, such as CETP, APOE,

Table 3 Effects of 1-year GHRT on anthropometric and biochemical variables in adults with GHD. Data are presented as mean \pm s.D.

\begin{tabular}{lcccc}
\hline & Baseline & 1 Year & Change & $\boldsymbol{P}$ value \\
\hline IGF1 $(\mu \mathrm{gg} / \mathrm{l})$ & $107.5 \pm 69.5$ & $251.1 \pm 122.6$ & $143.6 \pm 100.9$ & $<0.0001$ \\
IGF1 SDS & $-1.6 \pm 1.4$ & $1.3 \pm 2.3$ & $2.9 \pm 2.1$ & $<0.0001$ \\
TC $(\mathrm{mmol} / \mathrm{l})$ & $5.7 \pm 1.2$ & $5.5 \pm 1.4$ & $-0.2 \pm 1.1$ & 0.001 \\
LDL-C $(\mathrm{mmol} / \mathrm{l})$ & $3.7 \pm 1.1$ & $3.4 \pm 1.0$ & $-0.3 \pm 0.7$ & $<0.0001$ \\
HDL-C $(\mathrm{mmol} / \mathrm{l})$ & $1.3 \pm 0.4$ & $1.3 \pm 0.5$ & $0.07 \pm 0.4$ & 0.001 \\
TG $(\mathrm{mmol} / \mathrm{l})$ & $1.8 \pm 1.2$ & $2.1 \pm 4.3^{\mathrm{a}}$ & $0.3 \pm 3.9$ & 0.159 \\
Glucose $(\mathrm{mmol} / \mathrm{l})$ & $4.6 \pm 1.3$ & $4.8 \pm 1.2$ & $0.2 \pm 1.1$ & 0.001 \\
SBP $(\mathrm{mmHg})$ & $129.3 \pm 18.4$ & $127.6 \pm 17.6$ & $-1.7 \pm 14.9$ & 0.05 \\
DBP $(\mathrm{mmHg})$ & $78.6 \pm 11.4$ & $77.5 \pm 10.2$ & $-1.1 \pm 10.4$ & 0.07 \\
Weight $(\mathrm{kg})$ & $83.5 \pm 18.4$ & $83.0 \pm 18.3$ & $-0.5 \pm 6.2$ & 0.155 \\
BMI $\left(\mathrm{kg} / \mathrm{m}^{2}\right)$ & $28.2 \pm 5.3$ & $28.0 \pm 5.2$ & $-0.2 \pm 2.0$ & 0.05 \\
Waist circumference $(\mathrm{cm})$ & $98.6 \pm 13.0$ & $95.9 \pm 13.0$ & $-2.7 \pm 5.2$ & $<0.0001$ \\
W/H ratio & $0.95 \pm 0.07$ & $0.93 \pm 0.08$ & $-0.02 \pm 0.06$ & $<0.0001$ \\
\hline
\end{tabular}

SBP, systolic blood pressure; DBP, diastolic blood pressure; $W / H$, waist/hip.

aTwo outliers with no corresponding baseline values are included. 
Table 4 SNPs found to be associated with lipid concentrations at baseline in GHD adult carriers of two major alleles (MM) vs carriers of at least one minor allele ( $\mathrm{Mm}$ and $\mathrm{mm}$ ). Lipid concentrations are presented as mean \pm s.D.

\begin{tabular}{|c|c|c|c|c|c|}
\hline SNPs & Study parameters & $\mathbf{M M}(n)$ & $\mathbf{M m}$ and $\mathbf{~ m m}(n)$ & $P^{\mathrm{a}}$ & $\boldsymbol{P}_{\mathrm{adj}}^{\mathrm{b}}$ \\
\hline \multirow[t]{3}{*}{ CETP (rs708272) } & & GG (119) & GA and AA (198) & & \\
\hline & Basal TC & $5.48 \pm 1.12$ & $5.86 \pm 1.28$ & 0.009 & 0.006 \\
\hline & Basal HDL-C & $1.19 \pm 0.40$ & $1.31 \pm 0.41$ & 0.01 & 0.005 \\
\hline \multirow[t]{4}{*}{ CETP (rs1800775) } & & $\mathrm{CC}(105)$ & $\mathrm{CA}$ and $\mathrm{AA}(211)$ & & \\
\hline & Basal TC & $5.45 \pm 1.13$ & $5.84 \pm 1.26$ & 0.008 & 0.005 \\
\hline & Basal HDL-C & $1.19 \pm 0.40$ & $1.31 \pm 0.41$ & 0.01 & 0.01 \\
\hline & Basal LDL-C & $3.51 \pm 1.07$ & $3.79 \pm 1.14$ & 0.04 & 0.03 \\
\hline \multirow[t]{2}{*}{ CETP (rs3764261) } & & GG (160) & GT and TT (158) & & \\
\hline & Basal HDL-C & $1.18 \pm 0.38$ & $1.35 \pm 0.43$ & 0.0004 & 0.0004 \\
\hline \multirow[t]{2}{*}{$A P O B(\mathrm{rs} 693)$} & & $\mathrm{CC}(\overline{92})$ & CT and TT (219) & & \\
\hline & Basal HDL-C & $\begin{array}{l}1.18 \pm 0.35 \\
\operatorname{CC}(270)\end{array}$ & $\begin{array}{l}1.30 \pm 0.43 \\
\text { CT and TT (39) }\end{array}$ & 0.03 & 0.02 \\
\hline \multirow{2}{*}{ APOE (rs7412) } & Basal TC & $5.82 \pm 1.22$ & $5.00 \pm 1.02$ & 0.0001 & 0.0002 \\
\hline & Basal LDL-C & $3.78 \pm 1.12$ & $3.08 \pm 0.88$ & 0.0003 & 0.0004 \\
\hline \multirow[t]{2}{*}{ PPARG (rs10865710) } & & CC (177) & $C G$ and $G G(134)$ & & \\
\hline & Basal LDL-C & $3.81 \pm 1.13$ & $3.51 \pm 1.06$ & 0.02 & 0.02 \\
\hline \multirow[t]{2}{*}{ APOE/C (rs35136575) } & & CC (175) & CG and GG (136) & & \\
\hline & Basal TG & $1.88 \pm 1.29$ & $1.58 \pm 0.79$ & 0.02 & 0.007 \\
\hline
\end{tabular}

$A P O E / C, A P O E / C 1 / C 4 / C 2$ gene cluster.

${ }^{\text {a }} P$ value for an independent $t$-test between the genotype groups.

${ }^{\mathrm{b}} P$ value indicating association in ANCOVA.

APOB, APOE/C1/C4/C2 cluster, and PPARG, have an influence on serum lipid concentrations in patients with untreated GHD and that the APOB and PPARG genes could, to some extent, predict the changes in TC and LDL-C seen during GHRT.

GHRT induced a decrease in TC and LDL-C and an increase in HDL-C concentrations, with no changes in TG. These findings are in agreement with most previous studies $(4,29,30,31)$. There are, however, other reports that have not observed changes in serum lipids in response to $\mathrm{GH}$, suggesting wide-ranging variability in treatment response (32). Common genetic variants in genes involved in the regulation of lipid metabolism might influence the lipid response to GHRT, as suggested in two previous studies $(15,29)$. Therefore, we conducted this study using the candidate gene approach by selecting 20 SNPs in genes well known for their association with serum lipid concentrations in other populations $(16,17,18,19,20,21,22,23)$ and genes related to risk of coronary heart disease
$(17,19,20)$ and investigated their contribution to the lipid profile and lipid response to GHRT in GHD adults.

Heritability may explain $35-60 \%$ of variability in the plasma lipids, suggesting that genetic factors greatly influence the regulation of plasma lipids (33). Most of the polymorphisms that we studied had a MAF $\geq 10 \%$ and genotypic call rate $\geq 94.9 \%$, with no deviation from the HWE. Only two polymorphisms, rs1801177 in LPL and rs7412 in APOE, with a MAF $<10 \%$ were included in our analyses because of their clinical importance, as the former has been linked to higher remnant lipoproteins and lower $\alpha-2$ HDL-C particle levels (18) and the latter has been associated with most of the variance in serum LDL-C concentrations (34). However, using polymorphisms with MAFs $<10 \%$ has less statistical power (Table 2).

Twin studies have suggested that $\sim 50-60 \%$ of the variation in APOB plasma levels is genetically determined (35). APOB is critical to the synthesis, transport, and catabolism of TG-rich and cholesterol-rich

Table 5 SNPs found to be associated with changes in plasma lipid concentrations in response to 1-year GH therapy in GHD adult carriers of two major alleles (MM) vs carriers of at least one minor allele ( $\mathrm{Mm}$ and $\mathrm{mm}$ ). Changes in lipid concentrations are presented as mean \pm s.D.

\begin{tabular}{|c|c|c|c|c|c|c|c|}
\hline SNPs & Response & MM & $\mathrm{Mm}$ and $\mathrm{mm}$ & $\boldsymbol{P}^{\mathrm{a}}$ & $D^{\mathrm{b}}$ & $\boldsymbol{P}_{\mathrm{adj}}^{\mathrm{c}}$ & $P_{\text {corr }}{ }^{\mathrm{d}}$ \\
\hline \multirow[t]{3}{*}{$A P O B$ rs 676210} & & $\mathrm{GG}$ & GA and $A A$ & & & & \\
\hline & $\Delta \mathrm{TC}$ & $-0.34 \pm 0.89$ & $-0.06 \pm 0.72$ & 0.003 & 0.36 & 0.004 & 0.24 \\
\hline & $\Delta \mathrm{LDL}-\mathrm{C}$ & $-0.40 \pm 0.75$ & $-0.19 \pm 0.66$ & 0.016 & 0.19 & 0.024 & 0.78 \\
\hline \multirow[t]{2}{*}{ PPARG rs 10865710} & & & $\mathrm{CG}$ and $\mathrm{GG}$ & & & & \\
\hline & $\Delta \mathrm{TC}$ & $-0.33 \pm 0.87$ & $-0.01 \pm 0.81$ & 0.02 & 0.32 & 0.010 & 0.49 \\
\hline
\end{tabular}

TC, LDL-C, TG and HDL-C units are $\mathrm{mmol} / \mathrm{l}$.

${ }^{a} P$ value for an independent $t$-test between the genotype groups.

${ }^{b}$ Estimated difference between genotype groups in ANCOVA.

${ }^{\mathrm{C}} P$ value indicating association in ANCOVA.

${ }^{d} P$ value for ANCOVA corrected for 88 tests by permutation. 

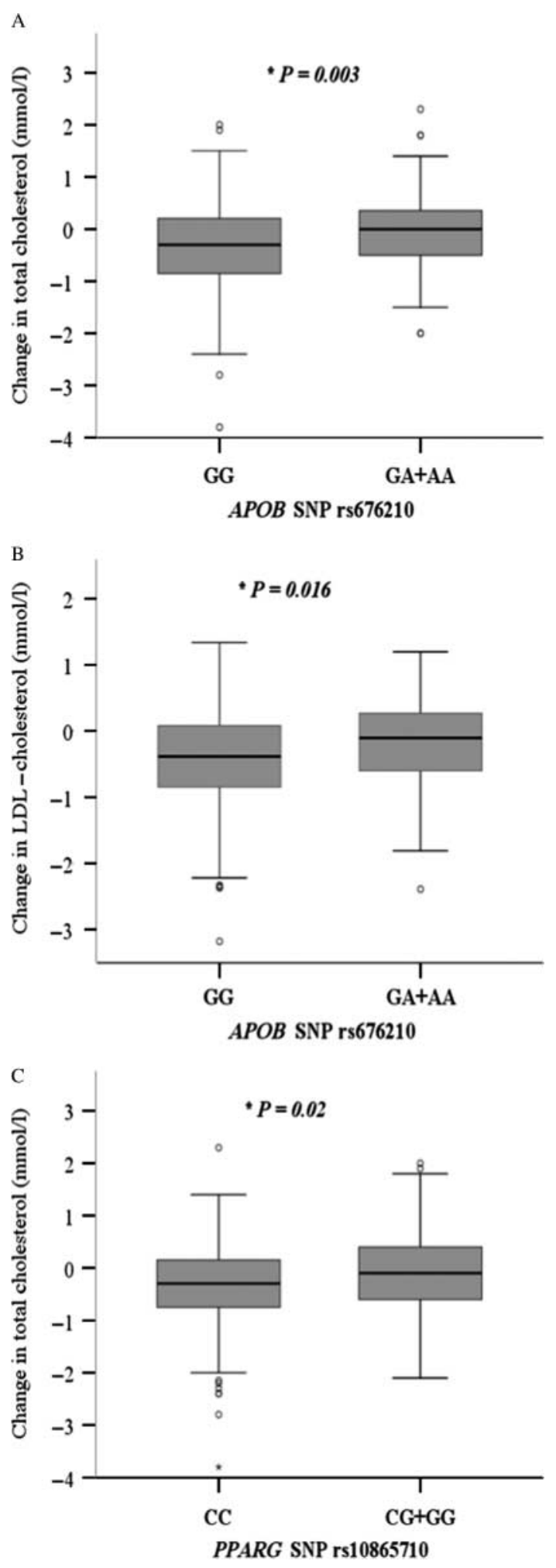

Figure 1 Individual changes in TC and LDL-C in response to $\mathrm{GH}$ replacement according to SNP rs676210 in the $A P O B$ gene (A, ${ }^{*} P=0.003$ and $\left.\mathrm{B},{ }^{*} P=0.016\right)$ and changes in $\mathrm{TC}$ according to SNP rs108657710 in the PPARG gene $\left(C,{ }^{\star} P=0.02\right)$. lipoproteins in the intestine and liver. This study is the first to examine the role of $A P O B$ polymorphisms in response to GHRT. GH has direct effects on the production and secretion of APOB-containing lipoproteins (VLDL, intermediate-density lipoprotein, and LDL) from the liver (2). $\mathrm{GH}$ increases the removal of circulating VLDL particles due to upregulating hepatic LDLRs and modifying the VLDL composition. It is therefore possible that polymorphisms within the $A P O B$ locus might contribute to variations in $\mathrm{TC}$ and LDL-C with GHRT. We indeed found the greatest reductions in TC and LDL-C concentrations in homozygous G carriers of SNP rs676210 in the APOB gene. It is not known how this polymorphism influences TC and LDL-C responses to GH, but one possible explanation is that it promotes structural changes in APOB, affecting the conversion of VLDL to LDL $(36,37$, 38). This could result in a reduction in the number of VLDL particles, or it might affect VLDL surface properties, or both. Another explanation is that this polymorphism accelerates LDL clearance by the LDLR (16) in patients with this genotype.

The PPARG gene regulates adipocyte differentiation and function and influences lipid metabolism by its activation through the STAT5B pathway. An in vitro study (22) demonstrated that the GH/STAT5B pathway could activate the promoter of the PPARG3 variant in 3T3-L1 cells and that PPARG SNP rs10865710 prevented this activation by abolishing the binding of STAT5B to this promoter. In a population-based study, the G allele of PPARG SNP rs10865710 was associated with increased $\mathrm{BH}$ and plasma LDL-C concentrations (22). However, we found that GHD G allele carriers had lower levels of LDL-C in relation to homozygous $C$ carriers. We also found that $\mathrm{G}$ allele carriers were less sensitive to GH in terms of reduced TC. These data further support interaction between the GH-IGF1 axis and the PPARG gene, both in the state of GHD and during GHRT.

The CETP gene, encoding CETP, enables the transfer of cholesteryl ester in plasma from HDL toward TG-rich lipoproteins (15). Genetic CETP deficiency is associated with very high HDL-C levels. CETP SNP rs1800775 has been shown to regulate CETP transcriptional activity in vitro (39). The SNPs rs708272 and rs1800775 in CETP are closely linked and they have been associated with increased HDL-C and decreased TG concentrations, but with negligible impact on LDL-C and APOB (40). CETP SNP rs3764261 also exhibited significant associations with HDL-C (41) and LDL-C (42). In our cohort of GHD adults, A allele carriers of SNPs rs708272 and rs1800775 and T allele carriers of SNP rs3764261 in the CETP gene showed higher serum HDL-C concentrations, in agreement with studies in other populations $(18,19,41,42)$. Furthermore, the A alleles of CETP SNPs rs708272 and rs1800775 were related to higher $\mathrm{TC}$, and the rs1800775 was also associated with increased LDL-C concentration. However, these 
associations have not been reported in other studies. A previous study found an association between CETP SNP rs1800775 and HDL-C response to GH treatment only in glucocorticoid-treated GHD patients (15), but we were unable to replicate these results in our study.

$A P O B$ SNP rs693 has been associated with increased LDL-C, TC, and APOB levels in the general population (16). Although these associations could not be found in our group of GHD adults, T allele carriers of this polymorphism showed higher serum HDL-C concentrations at baseline. This has not been reported in other populations and may therefore indicate an influence of the underlying disease and/or its treatment on the impact of this genotype on lipid metabolism.

The APOE gene is composed of three alleles $(\varepsilon 2, \varepsilon 3$, and $\varepsilon 4$ ) responsible for the synthesis of APOE (20). The APOE protein affects the metabolism of TC and TG by binding to receptors in the liver, mediating the clearance of chylomicron remnants and VLDL from the circulation. Two polymorphisms (rs7412 and rs429358) collectively form the $\varepsilon 2, \varepsilon 3$, and $\varepsilon 4$ alleles of the APOE gene. Allelic variation in the $A P O E$ has consistently been associated with plasma concentrations of $\mathrm{TC}$, LDL-C, and APOB (20). We observed that GHD adults carrying the T allele of APOE SNP rs7412 have lower TC and LDL-C levels at baseline, which is in agreement with a previous study (34).

On the basis of sequence alignment with the $A P O E / C 1 / C 4 / C 2$ gene cluster regulatory regions (21), SNP rs35136575 is located in the hepatic control region 2 (HCR2) that regulates hepatic expression and transcription of all four apolipoprotein genes in the cluster, $\sim 27 \mathrm{~kb}$ downstream of the APOE gene. The HCR2 contains protein-binding sequences. SNP rs35136575 could influence HCR2 enhancer function by altering key sequence elements in this region. Our results agree with a previous study demonstrating an association between plasma TG concentrations and APOE/C1/C4/C2 SNP rs35136575 (21). In our GHD patients, homozygous carriers of $\mathrm{C}$ allele had higher serum TG concentrations at baseline than $\mathrm{G}$ allele carriers.

This exploratory study has its limitations. The candidate gene approach selects genes based on those already well known for their associations with serum lipid concentration in other populations and does not exclude the possibility that other genes may be of greater importance. On the other hand, the design allows a targeted statistical approach, i.e. hypothesis generated. This suggests the importance of the polymorphisms in $A P O B$ and PPARG genes for the TC response to GHRT, although their statistical significance was lost after corrections for multiple testing (permutation analysis). These data therefore need to be confirmed by replication studies in an independent cohort. Although this is the largest study of its kind, the experience of other patient populations suggests that larger studies are needed for genotype-phenotype associations.
To conclude, this study is the first to look into how far multiple common variants in genes related to lipid metabolism contribute to individual differences in serum lipids of GHD adults and response to GH. Of the 20 SNPs investigated in this target gene approach, seven were found to have an influence on serum lipid concentrations in untreated GHD adults. After 1 year of GH replacement, two of these SNPs (APOB rs 676210 and PPARG rs10865710) were found to influence the treatment response in $\mathrm{TC}$ and $\mathrm{LDL}-\mathrm{C}$, although this finding did not remain significant after correction for multiple testing. Our findings may not be useful in clinical management but may turn out to have a biological importance regarding the influence of $\mathrm{GH}$ and IGF1 on the function of these genes and in the development of prediction models for response to GHRT.

\section{Supplementary data}

This is linked to the online version of the paper at http://dx.doi.org/10. 1530/EJE-12-0263.

\section{Declaration of interest}

E J L Barbosa, C A M Glad, A G Nilsson, H Filipsson Nyström, G Götherström, P-A Svensson, I Vinotti, B-Å Bengtsson, S Nilsson, and C $\mathrm{L}$ Boguszewski have nothing to declare. G Johannsson has received lecture honoraria from Pfizer, Novo Nordisk, Merk Serono, Eli Lilly, consulting fees from Viropharma and received research grants from Pfizer and Novo Nordisk.

\section{Funding}

This project has received financial support from the Swedish federal government under the LUA/ALF agreement, NovoNordisk and Pfizer.

\section{Acknowledgements}

The authors thank those who made this study possible, especially the late Sigrid Lindstrand. They also thank Ingrid Hansson, Jenny Tiberg, Lena Wirén, Anna-Lena Jönsson, Annika Reibring, Anna Olsson, and Annika Alklind at the Centre for Endocrinology and Metabolism, Sahlgrenska University Hospital, for their skillful technical support; the patients who participated in the study; and the Mutation Analysis Facility at Karolinska University Hospital for their work on the Sequenom part of this project, especially Linda Berglind and Kristina Duvefelt.

\section{References}

1 Abrams P \& Abs R. The lipid profile in adult hypopituitary patients with growth hormone deficiency. In Growth Hormone Deficiency in Adults - 10 years of KIMS, 1st edn, ch 12, pp 127-138. Eds R Abs \& U Feldt-Rasmussen. Oxford: Oxford PharmaGenesis Ltd., 2004.

2 Christ ER, Cummings MH, Albany E, Umpleby AM, Lumb PJ, Wierzbicki AS, Naoumova RP, Boroujerdi MA, Sönksen PH \& Russell-Jones DL. Effects of growth hormone $(\mathrm{GH})$ replacement therapy on very low density lipoprotein apolipoprotein B100 kinetics in patients with adult GH deficiency: a stable isotope study. Journal of Clinical Endocrinology and Metabolism 1999 84 307-316. (doi:10.1210/jc.84.1.307)

3 Barbosa EJL, Koranyi J, Filipsson H, Bengtsson BBoguszewski CL \& Johannsson G. Models to predict changes in 
serum IGF 1 and body composition in response to GH replacement therapy in GH-deficient adults. European Journal of Endocrinology 2010162 869-878. (doi:10.1530/EJE-09-0973)

4 Maison P, Griffin S, Nicoue-Beglah M, Haddad N, Balkau B \& Chanson P. Impact of growth hormone $(\mathrm{GH})$ treatment on cardiovascular risk factors in GH-deficient adults: a Metaanalysis of Blinded, Randomized, Placebo-Controlled Trials. Journal of Clinical Endocrinology and Metabolism 200489 2192-2199. (doi:10.1210/jc.2003-030840)

5 Garry P, Collins P \& Devlin JG. An open 36-month study of lipid changes with growth hormone in adults: lipid changes following replacement of growth hormone in adult acquired growth hormone deficiency. European Journal of Endocrinology 1996134 61-66. (doi:10.1530/eje.0.1340061)

6 Leese GP, Wallymahmed M, VanHeyningen C, Tames F, Wieringa G \& MacFarlane IA. HDL-cholesterol reductions associated with adult growth hormone replacement. Clinical Endocrinology 1998 49 673-677. (doi:10.1046/j.1365-2265.1998.00597.x)

7 Johannsson G, Bjarnason R, Bramnert M, Carlsson LM, Degerblad M, Manhem P, Rosen T, Thoren M \& Bengtsson BA. The individual responsiveness to growth hormone (GH) treatment in GH-deficient adults is dependent on the level of GH-binding protein, body mass index, age, and gender. Journal of Clinical Endocrinology and Metabolism $1996 \mathbf{8 1}$ 1575-1581. (doi:10. $1210 /$ jc.81.4.1575)

8 Cook DM, Ludlam WH \& Cook MB. Route of estrogen administration helps to determine growth hormone $(\mathrm{GH})$ replacement dose in GH-deficient adults. Journal of Clinical Endocrinology and Metabolism 199984 3956-3960. (doi:10.1210/jc.84.11.3956)

9 Boguszewski CL, Meister LH, Zaninelli DC \& Radominski RB. One year of GH replacement therapy with a fixed low-dose regimen improves body composition, bone mineral density and lipid profile of GH-deficient adults. European Journal of Endocrinology 2005152 67-75. (doi:10.1530/eje.1.01817)

10 Jorge AA \& Arnhold IJ. Growth hormone receptor exon 3 isoforms and their implication in growth disorders and treatment. Hormone Research 200971 (Suppl 2) 55-63. (doi:10.1159/000192438)

11 van der Klaauw AA, van der Straaten T, Baak-Pablo R, Biermasz NR, Guchelaar HJ, Pereira AM, Smit JW \& Romijn JA. Influence of the d3-growth hormone $(\mathrm{GH})$ receptor isoform on short-term and long-term treatment response to $\mathrm{GH}$ replacement in GH-deficient adults. Journal of Clinical Endocrinology and Metabolism 200893 2828-2834. (doi:10.1210/jc.2007-2728)

12 Giavoli C, Ferrante E, Profka E, Olgiati L, Bergamaschi S, Ronchi CL, Verrua E, Filopanti M, Passeri E, Montefusco L, Lania AG, Corbetta S, Arosio M, Ambrosi B, Spada A \& BeckPeccoz P. Influence of the d3GH receptor polymorphism on the metabolic and biochemical phenotype of GH-deficient adults at baseline and during short- and long-term recombinant human GH replacement therapy. European Journal of Endocrinology 2010163 361-368. (doi:10.1530/EJE-10-0317)

13 Barbosa EJ, Palming J, Glad CA, Filipsson H, Koranyi J, Bengtsson BA, Carlsson LM, Boguszewski CL \& Johannsson G. Influence of the exon 3-deleted/full-length growth hormone (GH) receptor polymorphism on the response to $\mathrm{GH}$ replacement therapy in adults with severe GH deficiency. Journal of Clinical Endocrinology and Metabolism 200994 639-644. (doi:10.1210/ jc.2008-0323)

14 Moyes VJ, Walker DM, Owusu-Antwi S, Maher KT, Metherell L, Akker SA, Monson JP, Clark AJ \& Drake WM. d3-GHR genotype does not explain heterogeneity in $\mathrm{GH}$ responsiveness in hypopituitary adults. Clinical Endocrinology 201072 807-813. (doi:10. $1111 / \mathrm{j} .1365-2265.2009 .03768 . x)$

15 Dullaart RPF, van den Berg G, van der Knaap AM, Dijck-Brouwer J, Dallinga-Thie GM, Zelissen PMJ, Sluiter WJ \& van Beek AP. HDL cholesterol response to $\mathrm{GH}$ replacement is associated with common cholesteryl ester transfer protein gene variation $(-629 \mathrm{C}>\mathrm{A})$ and modified by glucocorticoid treatment. European Journal of Endocrinology 2010162 227-234. (doi:10.1530/EJE-09-0742)

16 Benn M, Stene MC, Nordestgaard BG, Jensen GB, Steffensen R \& Tybjaerg-Hansen A. Common and rare alleles in apolipoprotein B contribute to plasma levels of low-density lipoprotein cholesterol in the general population. Journal of Clinical Endocrinology and Metabolism 200893 1038-1045. (doi:10.1210/jc.2007-1365)

17 Willer CJ, Sanna S, Jackson AU, Scuteri A, Bonnycastle LL, Clarke R, Heath SC, Timpson NJ, Najjar SS, Stringham HM, Strait J, Duren WL, Maschio A, Busonero F, Mulas A, Albai G, Swift AJ, Morken MA, Narisu N, Bennett D, Parish S, Shen H, Galan P, Meneton P, Hercberg S, Zelenika D, Chen WM, Li Y, Scott LJ, Scheet PA, Sundvall J, Watanabe RM, Nagaraja R, Ebrahim S, Lawlor DA, Ben-Shlomo Y, Davey-Smith G, Shuldiner AR, Collins R, Bergman RN, Uda M, Tuomilehto J, Cao A, Collins FS, Lakatta E, Lathrop GM, Boehnke M, Schlessinger D, Mohlke KL \& Abecasis GR. Newly identified loci that influence lipid concentrations and risk of coronary artery disease. Nature Genetics 200840 161-169. (doi:10.1038/ng.76)

18 Lamon-Fava S, Asztalos BF, Howard TD, Reboussin DM, Horvath KV, Schaefer EJ \& Herrington DM. Association of polymorphisms in genes involved in lipoprotein metabolism with plasma concentrations of remnant lipoproteins and HDL subpopulations before and after hormone therapy in postmenopausal women. Clinical Endocrinology 201072 169-175. (doi:10.1111/j. 1365-2265.2009.03644.x

19 Ridker PM, Pare G, Parker AN, Zee RY, Miletich JP \& Chasman DI. Polymorphism in the CETP gene region, HDL cholesterol, and risk of future myocardial infarction: genomewide analysis among 18 245 initially healthy women from the Women's Genome Health Study. Circulation. Cardiovascular Genetics 20092 26-33. (doi:10. 1161/CIRCGENETICS.108.817304)

20 Eichner JE, Dunn ST, Perveen G, Thompson DM, Stewart KE \& Stroehla BC. Apolipoprotein E polymorphism and cardiovascular disease: a HuGE review. American Journal of Epidemiology 2002 155 487-495. (doi:10.1093/aje/155.6.487)

21 Klos K, Shimmin L, Ballantyne C, Boerwinkle E, Clark A, Coresh J, Hanis C, Liu K, Sayre S \& Hixson J. APOE/C1/C4/C2 hepatic control region polymorphism influences plasma apoE and LDL cholesterol levels. Human Molecular Genetics $2008 \mathbf{1 7}$ 2039-2046. (doi:10.1093/hmg/ddn101)

22 Meirhaeghe A, Fajas L, Gouilleux F, Cottel D, Helbecque N, Auwerx J \& Amouyel P. A functional polymorphism in a STAT5B site of the human PPAR gamma 3 gene promoter affects height and lipid metabolism in a French population. Arteriosclerosis, Thrombosis, and Vascular Biology $2003 \quad 23 \quad 289-294$. (doi:10.1161/01.ATV.0000051382.28752.FE)

23 Fernandes-Rosa FL, Bueno AC, de Souza RM, de Castro M, dos Santos JE, Foss MC, Zennaro MC, Bettiol H, Barbieri MA \& Antonini SR. Mineralocorticoid receptor p.I180V polymorphism: association with body mass index and LDL-cholesterol levels. Journal of Endocrinological Investigation 201033 472-477.

24 Ho KKY. Consensus guidelines for the diagnosis and treatment of adults with GH deficiency II: a statement of the GH Research Society in association with the European Society for Pediatric Endocrinology, Lawson Wilkins Society, European Society of Endocrinology, Japan Endocrine Society, and Endocrine Society of Australia. European Journal of Endocrinology $2007 \mathbf{1 5 7}$ 695-700. (doi:10.1530/EJE-07-0631)

25 Landin-Wilhelmsen K, Wilhelmsen L, Lappas G, Rosén T, Lindstedt G, Lundberg PA \& Bengtsson B-Å. Serum insulin-like growth factor I in a random population sample of men and women: relation to age, sex, smoking habits, coffee consumption and physical activity, blood pressure and concentrations of plasma lipids, fibrinogen, parathyroid and osteocalcin. Clinical Endocrinology 199441 351-357. (doi:10.1111/j.1365-2265. 1994.tb02556.x)

26 Svensson J, Johannsson G \& Bengtsson BA. Insulin-like growth factor-I in growth hormone-deficient adults: relationship to population-based normal values, body composition and insulin tolerance test. Clinical Endocrinology 199746 579-586. (doi:10. 1046/j.1365-2265.1997.1851001.x)

27 Wiklund O, Fager G, Olofsson SO, Wilhelmsson C \& Bondjers G. Serum apolipoprotein levels in relation to acute myocardial 
infarction and its risk factors - determination of apolipoprotein D. Atherosclerosis $1980 \quad 37$ 631-636. (doi:10.1016/0021-9150 (80)90070-2)

28 Friedewald WT, Levy RI \& Fredrickson DS. Estimation of the concentration of low-density lipoprotein cholesterol in plasma, without use of the preparative ultracentrifuge. Clinical Chemistry 197218 499-502.

29 Johannsson G, Oscarsson J, Rosen T, Wiklund O, Olsson G, Wilhelmsen L \& Bengtsson BA. Effects of 1 year of growth hormone therapy on serum lipoprotein levels in growth hormonedeficient adults. Influence of gender and Apo(a) and ApoE phenotypes. Arteriosclerosis, Thrombosis, and Vascular Biology 199515 2142-2150. (doi:10.1161/01.ATV.15.12.2142)

30 Johannsson G, Bengtsson BA, Andersson B, Isgaard J \& Caidahl K. Long-term cardiovascular effects of growth hormone treatment in GH-deficient adults. Preliminary data in a small group of patients. Clinical Endocrinology 199645 305-314. (doi:10.1046/j.13652265.1996.00820.x)

31 Gotherstrom G, Bengtsson BA, Bosaeus I, Johannsson G \& Svensson J. A 10-year, prospective study of the metabolic effects of growth hormone replacement in adults. Journal of Clinical Endocrinology and Metabolism 200792 1442-1445. (doi:10. 1210/jc.2006-1487)

32 Sesmilo G, Biller BM, Llevadot J, Hayden D, Hanson G, Rifai N \& Klibanski A. Effects of growth hormone administration on inflammatory and other cardiovascular risk markers in men with growth hormone deficiency, A randomized, controlled clinical trial. Annals of Internal Medicine 2000133 111-122.

33 Weiss LA, Pan L, Abney M \& Ober C. The sex-specific genetic architecture of quantitative traits in humans. Nature Genetics 200638 218-222. (doi:10.1038/ng1726)

34 Bennet AM, Reynolds CA, Gatz M, Blennow K, Pedersen NL \& Prince JA. Pleiotropy in the presence of allelic heterogeneity: alternative genetic models for the influence of APOE on serum LDL, CSF amyloid- $\beta 42$, and dementia. Journal of Alzheimer's Disease 201022 129-134. (doi:10.3233/JAD-2010-100864)

35 Beekman M, Heijmans BT, Martin NG, Pedersen NL, Whitfield JB, Defaire U, van Baal GC, Snieder H, Vogler GP, Slagboom PE \& Boomsma DI. Heritabilities of apolipoprotein and lipid levels in three countries. Twin Research 20025 87-97. (doi:10.1375/ 1369052022956 )

36 Sunyaev S, Ramensky V, Koch I, Lathe W III, Kondrashov AS \& Bork P. Prediction of deleterious human alleles. Human Molecular Genetics 200110 591-597. (doi:10.1093/hmg/10.6.591)
$37 \mathrm{Ng}$ PC \& Henikoff S. SIFT: predicting amino acid changes that affect protein function. Nucleic Acids Research $2003 \mathbf{3 1}$ 3812-3814. (doi:10.1093/nar/gkg509)

38 Wojczynski MK, Gao G, Borecki I, Hopkins PN, Parnell L, Lai CQ, Ordovas JM, Chung BH \& Arnett DK. Apolipoprotein B genetic variants modify the response to fenofibrate: a GOLDN study. Journal of Lipid Research 201051 3316-3323. (doi:10.1194/jlr. P001834)

39 Dachet C, Poirier O, Cambien F, Chapman J \& Rouis M. New functional promoter polymorphism, CETP/-629, in cholesteryl ester transfer protein (CETP) gene related to CETP mass and high density lipoprotein cholesterol levels: role of Sp1/Sp3 in transcriptional regulation. Arteriosclerosis, Thrombosis, and Vascular Biology 200020 507-515. (doi:10.1161/01.ATV.20.2.507)

40 Thompson A, Di Angelantonio E, Sarwar N, Ergou S, Saleheen D, Dullaart RPF, Keavney B, Ye Z \& Danesh J. Association of cholesteryl ester transfer protein genotypes with CETP mass and activity, lipid levels, and coronary risk. Journal of the American Medical Association 2008299 2777-2788. (doi:10.1001/jama. 299.23.2777)

41 Sarzynski MA, Jacobson P, Rankinen T, Carlsson B, Sjostrom L, Carlsson LM \& Bouchard C. Association of GWAS-based candidate genes with HDL-cholesterol levels before and after bariatric surgery in the Swedish obese subjects study. Journal of Clinical Endocrinology and Metabolism 201196 E953-E957. (doi:10. 1210/jc.2010-2227)

42 Talmud PJ, Drenos F, Shah S, Shah T, Palmen J, Verzilli C, Gaunt TR, Pallas J, Lovering R, Li K, Casas JP, Sofat R, Kumari M, Rodriguez S, Johnson T, Newhouse SJ, Dominiczak A, Samani NJ, Caulfield M, Sever P, Stanton A, Shields DC, Padmanabhan S, Melander O, Hastie C, Delles C, Ebrahim S, Marmot MG, Smith GD, Lawlor DA, Munroe PB, Day IN, Kivimaki M, Whittaker J, Humphries SE \& Hingorani AD. Gene-centric association signals for lipids and apolipoproteins identified via the HumanCVD BeadChip. American Journal of Human Genetics 200985 628-642. (doi:10.1016/j.ajhg.2009.10.014)

Received 26 March 2012

Revised version received 13 June 2012

Accepted 19 June 2012 